\title{
O século XX para o Feminismo no Brasil
}

\author{
El siglo XX para el feminismo en Brasil \\ The 20th century for Feminism in Brazil
}

\author{
Tascieli Feltrin ${ }^{1}$ \\ Natália Lampert Batista ${ }^{2}$ \\ Guilherme Carlos Correa ${ }^{3}$ \\ Elsbeth Léia Spode Becker ${ }^{4}$
}

\begin{abstract}
Resumo
O século XX possui marcas importantes para se pensar as transformações que diversos extratos sociais sofreram, no Brasil, em especial as mulheres. Tais como os processos de urbanização, imigração e industrialização do país, e sua consequente absorção do trabalho feminino, como também a necessidade de incorporação das mulheres nos quadros militares de apoio durante a Segunda Guerra Mundial, a feminização do magistério e o enfrentamento à estados repressores como os instalados no Estado Novo e na Ditadura Militar. No presente trabalho, pretende-se percorrer brevemente a composição de forças que interferiram ou atravessaram a questão feminina, no Brasil, e com uma atenção maior, os movimentos em prol da autonomia e igualdade de tratamento entre mulheres e homens nas primeiras décadas do século $\mathrm{XX}$, representados pelos movimentos Anarcofeministas e Sufragistas. Com destaque estes acontecimentos são trazidos para pensar a condição das mulheres em sua pluralidade de situações étnico-sociais e sua repercussão dentro da sociedade brasileira, para isso, buscamos em jornais e periódicos da época, além de obras referências para a temática, conhecer quais eram as pautas femininas e em que condições se desenvolviam.
\end{abstract}

Palavras-Chave: Segunda Guerra Mundial, Estado Novo, Movimentos Anarcofeminista e Sufragista.

\section{Resumen}

El siglo XX posee marcas importantes para pensar las transformaciones que diversos extractos sociales sufrieron, en Brasil, en especial las mujeres. Tales como los procesos de urbanización, inmigración e industrialización del país, y su consiguiente absorción del trabajo femenino, así como la necesidad de incorporación de las mujeres en los cuadros militares de apoyo durante la Segunda Guerra Mundial, la feminización del magisterio y el enfrentamiento a los estados represores como los instalados en el Estado Novo y en la Dictadura Militar. En el presente trabajo, se pretende recorrer brevemente la composición de fuerzas que interfirieron o atravesaron la cuestión femenina, en Brasil, y con una atención mayor, los movimientos en pro de la autonomía e igualdad de trato entre mujeres y hombres en las primeras décadas del siglo XX, representados por los movimientos Anarcofeministas y Sufragistas. Con estos acontecimientos se traen para pensar la condición de las mujeres en su pluralidad de situaciones étnico-sociales y su repercusión dentro de la sociedad brasileña, para ello, buscamos en periódicos y periódicos de la época, además de obras referencias para la temática, conocer cuáles eran las pautas femeninas y en qué condiciones se desarrollaban.

Palabras Clave: Segunda Guerra Mundial, Estado Novo, Movimientos Anarcofeministas y Sufragistas.

\footnotetext{
${ }^{1}$ Mestra em Educação; Universidade Federal de Santa Maria - UFSM, Santa Maria, Rio Grande do Sul, Brasil; tascifeltrin@gmail.com.

${ }^{2}$ Mestra em Geografia; Universidade Federal de Santa Maria - UFSM, Santa Maria, Rio Grande do Sul, Brasil; natilbatista3@gmail.com.

${ }^{3}$ Pós Doutor em Educação; Pontifícia Universidade Católica do Rio Grande do Sul - PUCRS, Santa Maria, Rio Grande do Sul, Brasil; gcarloscorrea@gmail.com.

4 Doutora em Agronomia; Universidade Federal de Santa Maria - UFSM, Santa Maria, Rio Grande do Sul, Brasil; elsbeth.geo@gmail.com.
} 


\begin{abstract}
The twentieth century has important marks to think about the transformations that several social extracts have suffered in Brazil, especially women. Such as the processes of urbanization, immigration and industrialization of the country, and its consequent absorption of women's work, as well as the need to incorporate women into military support tables during World War II, feminization of the teaching profession and confrontation with repressive states such as those installed in the Estado Novo and the Military Dictatorship. In the present work, we intend to briefly review the composition of forces that interfered or crossed the feminine question in Brazil, and with greater attention, the movements for autonomy and equal treatment between women and men in the first decades of the twentieth century, represented by the Anarchofeminist and Sufragist movements. With emphasis these events are brought to think about the condition of the women in their plurality of ethnic-social situations and their repercussion within the Brazilian society, for that, we look for in newspapers and periodicals of the time, besides reference works for the subject, to know which were the female prompts and under what conditions.
\end{abstract}

Keywords: World War II, Estado Novo, Anarchofeminist and Sufragist Movements.

\title{
1. Introdução
}

A conjuntura político-social do Brasil no final do século XIX apresentava os principais elementos de transmutação das condições de existência no país, inclusive das mulheres. Dentre tais elementos, tomam parte a abolição oficial da escravatura em 1888, a conversão do sistema monárquico para o republicano em 1889, a abertura dos postos de trabalho para receber os desempregados excedentes na Europa, o prelúdio da industrialização da economia e a infiltração de correntes ideológicas diversas e efervescentes que oportunizam os acontecimentos e transformações ocorridas no século XX. Tais fatores ligam-se diretamente a um novo diagnóstico sobre a situação do país. Brevemente aborda-se, neste estudo, cada um deles e sua relação com o cenário feminista.

Além das mudanças ocorridas no país as vésperas do início do século XX, alguns outros fatores internos e externos são de grande relevância para a instalação de muitas transformações relacionadas ás questões femininas na sociedade durante o século. Entre elas destacam-se a Segunda Guerra Mundial, o início do Estado Novo, e o florescimento dos Movimento Anarquista e Sufragista, no Brasil. Com alguma ênfase, estes acontecimentos são trazidos para pensar a condição das mulheres em sua pluralidade de situações étnico-sociais e sua repercussão dentro da sociedade brasileira, para isso, buscamos em jornais e periódicos da época, além de obras referências para a temática, conhecer quais eram as pautas femininas e em que condições se desenvolviam.

Nesse sentido, nas linhas as seguir intencionamos percorrer brevemente a composição de forças que interferiu ou atravessou a questão feminina no século $\mathrm{XX}$, no Brasil, e com uma atenção maior, os movimentos em prol da autonomia e igualdade de tratamento entre mulheres e homens nas primeiras décadas do século. 


\section{As bases da mudança}

Durante o século XIX algumas mudanças significativas foram sendo consolidadas na sociedade brasileira no tocante às mulheres. Em 1827, por exemplo, foi promulgado o Decreto Imperial, de 15 de outubro de 1827, ou Primeira Lei Geral relativa ao Ensino Elementar, o qual permitia que as meninas frequentassem a escola elementar. Somente em 1879, através do Decreto $\mathrm{n}^{\circ} 7.247$, de 19 de abril de 1879 , é derrubada a proibição ao ingresso em instituições de ensino de outras modalidades, como a superior. A autorização por parte do Estado, no entanto, não foi suficiente para que se popularizasse a educação feminina no país, visto que, as famílias que insistiam em permitir a educação escolar de suas filhas sofriam forte preconceito social.

\footnotetext{
Art. $2^{\circ}$ Até se mostrarem habilitados em todas as disciplinas que constituem o programma das escolas primarias do $1^{\circ}$ gráo, são obrigados a frequental-as, no municipio da Còrte, os individuos de um e outro sexo, de 7 a 14 annos de idade. Esta obrigação não comprehende os que seus pais, tutores ou protectores provarem que recebem a instrucção conveniente em escolas particulares ou em suas proprias casas, e os que residirem a distancia maior, da escola publica ou subsidiada mais proxima, de um e meio kilometro para os meninos, e de um kilometro para as meninas. $\S 1^{\circ}$ Todos aquelles que, tendo em sua companhia meninos ou meninas nas condições acima mencionadas, deixarem de matriculal-os nas escolas publicas, ou de proporcionar-lhes em estabelecimentos particulares ou em suas casas a instrucção primaria do $1^{\circ}$ gráo, sejam pais, mais, tutores ou protectores, ficam sujeitos a uma multa de 20 a $100 \$ 000$. (BRASIL, 1879, Decreto $\mathrm{n}^{\circ} 7.247$, sic).
}

O Decreto $n^{\circ} 7.247$ determinava que algumas disciplinas deveriam ser exclusivas para as meninas como Costura simples, Noções de economia doméstica e Trabalhos de agulha enquanto que nas disciplinas de Noções de economia social e Prática manual de ofícios sua presença não era permitida. Importante salientar que as leis educacionais não atingiam grande parte das mulheres do povo, devido à precariedade do número de escolas e à legalização da escravidão. Para além do âmbito educacional, a situação feminina fora atravessada pela influência de importantes movimentos fortalecidos no final do século XIX, como o Movimento Abolicionista e o Republicano.

A abolição da escravatura, apesar de não advinda de uma organização interna, apresenta-se como uma tentativa de alinhamento às potencias europeias, sob forte pressão da Inglaterra principalmente, e que acaba por fomentar, no cenário nacional, um avivamento das manifestações sociais em busca de espaço e representatividade. Alia-se a isto, a Proclamação da República que inaugura um período sem antecedentes de "liberdade" política e administrativa. Consequência direta do fim da mão-de-obra escrava, a abertura para imigração estrangeira se alinha ao nascimento dos processos de industrialização e das primeiras fábricas 
no Brasil, as quais, abrirão os primeiros postos de trabalho, reconhecidos, para mulheres, até então atuantes nas atividades invisíveis e de desprestígio. Como também, influencia diretamente na penetração dos ideais fascistas, nazistas, e anarquistas no país, e que em polos opostos modularam o entendimento e as ações de mulheres em seus diversos papéis sociais.

Devido aos longos anos de escravidão do povo negro e à crescente utilização de discursos eugenistas em áreas como a educação, saúde, arquitetura e urbanismo, a situação das mulheres negras ou mestiças era ainda pior que a enfrentada pelas demais mulheres. Mesmo após o fim da legalização da escravidão, era comum a relação do corpo negro com a propensão a sexualidade, sendo que em caso de estupros ou violações a cor da vítima era um elemento importante para o julgamento do caso. Segundo Cortes (2006) se comprovada a presença de traços africanos na vítima, isto servia de atenuante ao crime, pois se entendia que devido a sua suposta tendência à lascívia, as mulheres negras consentiam e até provocavam este tipo de comportamento nos homens.

O cenário que se apresentava no Brasil do início do século XX, revela um Estado republicano ainda frágil e dependente da influência de elementos do antigo regime, e que buscava se firmar sobre o fortalecimento da repressão policial, da interferência na vida privada e da legalização da covardia sobre as classes subalternas. Dessa forma, o período poder ser representado pelo embate entre forças opostas e a criação de redutos pelos iguais. Assim, surgem os primeiros sindicatos e agremiações de operários unidos para enfrentar as grandes oligarquias e os industriais em pleno crescimento, visto que o Estado encontrava-se submetido à economia. Abrem-se os primeiros espaços para a circulação de ideias contrárias à influência religiosa, e aos privilégios concedidos a clérigos. Criam-se jornais comprometidos com a divulgação de temas próprios de cada segmento ou grupo. E organizam-se os primeiros grupos de mulheres, de que se tem registros, ao redor de temas femininos.

O autoritarismo, o medo e a ignorância eram os mecanismos presentes nos discursos proliferados sobre as mulheres, pelas duas instituições de maior prestígio no início do século XX. Estado e Igreja compartilhavam da crença de que entre os sexos havia um acordo histórico em que os homens adquiriram um poder institucional e social sobre as mulheres e estas, para o bem da conservação da espécie, abnegavam de suas vontades em respeito aos seus pais, maridos e filhos, pois era para o bem destes últimos que deveria convergir todos os esforços femininos. Justificando, assim, as proibições ao trabalho assalariado, ao sufrágio feminino, ao mundo acadêmico, ao conhecimento sobre si e sua anatomia, ao acesso a métodos anticonceptivos, à liberdade de ir, vir e pensar, ao recebimento de heranças e títulos, 
etc. Observe as palavras de José Oiticica, no fragmento abaixo, extraído do periódico A VIDA, que circulava em 1915, o qual retrata a situação da mulher nesse período.

Si considerarmos a situação da mulher. Que faz ela entre nós? A aristocrata dirije a caza, isto é dá ordens, lê romances ou administra associações de caridade e irmandades católicas. A da classe média, juntamente com alguns criados faz o serviço da casa: cozinha, lava, engoma, coze, cuida dos filhos [...] A mulher do povo, a proletária, essa nem mesmo tem possibilidade de escolher serviço. Lava, cozinha, engoma, coze, serve nas fábricas, é criada. Não há em que desenvolver aptidões neste terreno. (A VIDA n ${ }^{\circ} 3,1915$, p.5, sic)

Com o avançar do século, a necessidade de se aproveitar toda a força de trabalho humano lançou certa visibilidade ao trabalho feminino. As mulheres das classes economicamente mais baixas sempre tiveram importância substancial para o sustento de suas famílias, no entanto, suas atividades laborais não eram reconhecidas socialmente.

A condição feminina apartava-se das diferenças de classe, pois mesmo que uma mulher fosse detentora de uma fortuna ainda assim ela não seria dona de sua própria vontade perante a sociedade, necessitando sempre o aval masculino. Ou seja, "as favorecidas com heranças, incapazes de jerir, por falta de preparo, os seus haveres, caem nas mãos dos exploradores" (A VIDA nº4, 1915, p.54, sic).

O desenvolvimento das indústrias e a precarização da vida urbana impulsionou as mulheres a disputarem com os homens lugar nas fábricas. Seu trabalho, no entanto, não recebia a mesma valoração que o trabalho masculino, o que mantinha legalmente a condição de dependência das mulheres. Enquanto um número expressivo das mulheres negras realizava trabalhos considerados invisíveis pela sociedade da época (lavar, passar, trabalho doméstico) e, assim, proviam o sustento de suas famílias.

\footnotetext{
No engenho dos Norte pága-se a um trabalhador do campo r $\$ 000^{5}, 800$ rs., ou 600 rs. mesmo, a seco; a uma mulher 500 rs. no máximo, a uma criança meia pataca. Dez tostões por dia, a um homem que trabalha ao sol no cabo da enxada, durante 12 horas; dez tostões para comer, vestir-se, criar os filhos. Qual pode ser a alimentação desse homem, dessas mulheres, dessas crianças? A que eles têm: pirão de farinha agua e sal, bacalhau, ou quando muito, um peixe escasso, pescado no rio com gereré. (A VIDA, $\mathrm{n}^{\circ} 1,1914$, p.07-08, sic)
}

Para se alcançar as implicações da quantia paga às mulheres, um exemplar da revista $A$ Vida, um periódico anarquista de preço popular, do qual se retirou a citação acima custava 200 rs (réis), enquanto que as mulheres empregadas nos engenhos do Norte do Brasil recebiam 500 reis por um dia de trabalho.

\footnotetext{
${ }^{5}$ Aqui há claramente um erro de tipografia. Onde lê-se r $\$ 000$, deveria estar r $\$ 1000$.
} 
Na sociedade moderna a mulher está sujeita aos mesmos trabalhos físicos, com o mesmo número de horas e menor salário que o homem. Quem percorre as lavouras pode ver o estado de depauperamento precoce das mulheres do povo. Ele se alardeia nos hospitais, em toda a sua hediondez. [...] não é tudo. Acrescente ao excesso de trabalho à má alimentação consequente à insuficiência do salário. (A VIDA $\left.\mathrm{n}^{\circ} 1,1914, \mathrm{p} .07\right)$

Apesar da necessidade das fábricas, havia uma pressão por parte da Igreja Católica e também por parte de políticos e magistrado mais conservadores para que as mulheres não ocupassem cargos remunerados e permanecessem em casa, cuidando do lar. Essa situação, no entanto, não se aplicava a boa parte da população mais pobre, que dependia do trabalho remunerado de todos os membros da família para sua subsistência.

Trabalhavam de sol a sol nas lavouras ou nos porões das fábricas, recebiam os piores serviços, mal tinham para comer. Iniciavam-se nesta rotina aos seis anos de idade, por vezes antes, trabalhavam até 16 horas por dia, levavam os filhos, por necessidade, para a sujeira e a violência de seu trabalho e, logo que estes podiam, eram empregados, também em condições sub-humanas. Esta era a dura realidade das mulheres no início do século XX no Brasil.

A influência desse pensamento sobre as mulheres resultou na 'ilegalidade' e 'desprestígio' do trabalho feminino e fortaleceu um senso comum de que o trabalho doméstico, o cuidado dos filhos e outras atividades que, as mulheres exerciam para si ou para outros, não era em si um trabalho. Em cargos públicos e outras atividades de maior prestígio, com exceção do magistério, não se admitia a atuação feminina.

\section{As Anarcofeministas e as Sufragistas no Brasil}

Nesse cenário desolador para as mulheres, despontam figuras envolvidas com o pensamento libertário, as quais acreditavam que mudar a condição das mulheres era prérequisito para que a humanidade avançasse mais rapidamente em sua evolução científica e moral. Entre estas mulheres, foram importantes pensadoras e divulgadoras das ideias anarquistas nomes como Louise Michel ${ }^{6}$, Lucy Parson ${ }^{7}$, Luce Fabri ${ }^{8}$ e Emma Goldman ${ }^{9}$ de reconhecimento internacional e no Brasil Elvira Boni ${ }^{10}$, Maria Lacerda de Moura ${ }^{11}$, Matilde

\footnotetext{
${ }^{6}$ Educadora Anarquista, criadora do grupo "O Direito da Mulher" e com participação na Comuna de Paris, em 1871.

${ }^{7}$ Sindicalista americana com participação em eventos como a Greve Geral de $1^{\circ}$ de Maio, em 1886.

${ }^{8}$ Militante Anarquista de grande vulto para o Anarcofeminismo uruguaio.

${ }^{9}$ Ativista e escritora anarquista, defendia o uso de métodos contraceptivos, com atuação em países como os Estados unidos e a Rússia.

${ }^{10}$ Fundadora da União das Costureiras, em 1919, participou ativamente da organização de greves das costureiras, de teatros populares e da edição da revista libertária Renovação.
} 
Magrassi $^{12}$, Isabel Cerruti ${ }^{13}$, Maria Alles ${ }^{14}$, e muitas outras, a que a história concedeu o esquecimento, ergueram suas vozes em defesa de homens, de mulheres e do pensamento livre.

As Anarcofeministas ou Libertárias questionaram a legalidade deste contrato social de sujeição a que as mulheres estavam expostas. Em suas obras criticam a concepção de maternidade como um dom, defendendo que esta concepção é uma prisão criada para manter as mulheres sob a tutela dos homens, da igreja e do Estado. Seu lema era: Nem amo, nem Deus, nem marido.

A superioridade manifesta da mulher como criadora de vida para perpetuar a espécie, a maternidade, o aleitamento, os cuidados para com a criança e todas as consequências dessa escravidão que a sociedade faz pesar, por isso mesmo, sobre os frágeis ombros femininos- deveriam bastar para dar à mulher o direito a viver integralizada na comunhão político-social. (MOURA, 1933, p.12).

Suas falas denunciaram a covardia dessa sociedade que relegou os piores papéis às mulheres e lhes negou a autonomia sobre si, o acesso à educação, à saúde e ao cuidado, o protagonismo nas relações políticas e sociais e a possibilidade de pensar fora dos modelos propostos.

A mulher sobretudo se tem conservado numa ignorância sistemática. Só modernamente ela se vai revoltando contra a opressão do homem. Vêde porem que tenaz resistência ela suporta da parte dos graúdos. Ainda hoje é malvista a moça que se atira aos estudos superiores. (A VIDA nº2,1914, p.07, sic)

Apesar da existência de leis educacionais que garantiam o direito à educação feminina muito pouco se avançou nessa área nos primeiros anos do século XX. Nesse sentido, pode-se dizer que as jovens pertencentes às classes mais abastadas possuíam uma leve vantagem sobre as demais, nada, porém que as fizessem donas de si, ao contrário, eram educadas para a sujeição. As jovens, de alta classe recebiam algum tipo de instrução, nada semelhante à reservada aos homens. Elas aprendiam a ler e escrever minimamente. Quando não recebiam esta instrução em casa, por meio de um preceptor e acompanhadas de alguém da família, eralhes permitido frequentar uma escola regida por uma instituição religiosa que garantisse o não recebimento de nenhum tipo de incentivo a rebelarem-se contra a escolha de cônjuge feita

\footnotetext{
${ }^{11}$ Educadora, ativista e escritora libertária, possui uma vasta coleção de obras dedicadas à difusão do Anarquismo no Brasil e oposição ao pensamento fascista. Se destaca também por sua defesa às causas feministas e ao amor livre.

${ }^{12}$ Imigrante italiana com forte influência no tetro anarquista no Brasil.

13 Colaboradora de inúmeros jornais anarquistas, como A Plebe, militava em prol das causas feministas em conferências, comícios públicos, e protestos. Fez parte do Centro Educativo Feminino e da Liga Feminina Internacional.

${ }^{14}$ Libertária envolvida com a organização Anarcossindicalista.
} 
pela família. Sua educação centrava-se em bem bordar, costurar e atender as necessidades do lar e do futuro marido. Pois não era outra a intenção dessas escolas para moças do que prepará-las para o casamento. Aprendiam alguma coisa de Francês, canto e piano habilidades valorizadas na conquista de melhores pretendentes.

A educação ministrada em Sião ${ }^{15}$ é a educação da luva e do savoir vivre envernizada com as crendices e mentiras mais abomináveis. Aprende-se ali desenho, aritmética primária, francez, geografia, mnemônica, historia sagrada e resa. Nem uma palavra de ciências físicas e naturais. (A VIDA nº 5, 1915, p.74).

A conjuntura de desenvolvimento da mulher a estes tempo não lhes favorecia em nada. No entanto, os movimentos por melhores condições de vida, greves, e lutas por direitos impeliu também as mulheres a buscarem sua emancipação e sobretudo conquistarem o direito a uma educação livre de preconceitos e restrições. A greve se constitui em uma marcante estratégia anarquista, através da qual o movimento libertário auxiliou milhares de operários e demais trabalhadores a se organizarem em prol de melhores condições de trabalho. Tinha um caráter educativo para os anarquistas, visto que proporcionava aos trabalhadores contato com a autogestão, possibilitava a troca de conhecimentos entre eles, esclarecia os grevistas acerca da estrutura capitalista e jurídica do país.

Para os libertários, a greve era a melhor expressão de seu princípio da Ação Direta. Uma das causas de greves mais importantes na história do Anarcossindicalismo foi a luta pela equiparação salarial entre homens, mulheres e crianças. Seu lema na época era: Para igual trabalho, igual salário. Em seguida, os operários passaram a reivindicar a existência de um salário mínimo para cada classe, recebimento de indenizações por danos físicos durante o trabalho, licença maternidade para as gestantes, lei de férias, Código dos Menores e Lei de Sindicalização.

A mobilização operária, através das greves, definiu novas condições de trabalho para os operários, como a redução da jornada de trabalho diária de 16 horas, a proibição do trabalho infantil para menores de 12 anos, o fim da jornada noturna para mulheres e crianças e a abolição da diminuição e do atraso dos salários.

A inserção das mulheres nas escolas e centros acadêmicos foi resultado de um caminhar lento e gradual. A conquista de alguma autonomia e de reconhecimento de sua liberdade e capacidade de aprender os conhecimentos historicamente construídos por homens foi um reflexo conjunto de avanços internacionais e campos de lutas nacionais. No cenário

\footnotetext{
${ }^{15}$ Monte Sião, colina bíblica considerada a Terra Prometida por Deus, a Israel para os cristãos.
} 
nacional destaca-se a atuação de movimentos feministas e de outras vertentes que entendiam a singularidade da condição feminina e a necessidade de se dissolver as superstições e preconceitos enrijecidos nesta sociedade.

Nesse sentido, pode-se perceber que o pensamento Libertário no Brasil, abre espaço para a atuação das mulheres e para a divulgação de sua condição e pensamentos. Naquele início de século, mulheres identificadas com a causa libertária tiveram importante participação no desenvolvimento de atividades que denunciavam a condição de inferioridade da mulher e construíram espaços de atuação, em que estas tinham voz e vez.

Os libertários defendiam não só a educação das mulheres, mas, mais além propunham uma coeducação dos sexos, que acabaria com os preconceitos e com a dominação de uns sobre outros. Além de desenvolverem iniciativas educativas não escolares que possuíam vasto alcance no território nacional, como apresentações teatrais, festas, publicações de jornais e livros, a abertura de bibliotecas. Iniciativas acessíveis a todos, principalmente as pessoas que não tinham condição de se instruir e que serviam de estratégia de combate ao obscurantismo da igreja e ao despotismo do estado esclarecendo a população para sua condição frente a estas instituições de domínio popular.

Tanto as iniciativas educacionais libertárias não escolares quanto as mulheres que se destacaram dentro do movimento possuem relevância histórica para o desenvolvimento da condição da mulher. Muitas das mulheres libertárias contribuíram e tomaram parte de outros movimentos, como por exemplo, Maria Lacerda de Moura que em meados da década de 20 fundou com Bertha Lutz, precursora do Movimento Sufragista no Brasil, a Liga para a Emancipação Intelectual das Mulheres (LEM). No entanto, as divergências epistemológicas entre ambas resultaram no fim da associação. Em 1922, Lutz funda a Federação para o Progresso Feminino, em prol do sufrágio feminino e das questões legais do divórcio.

Bastante atuante no país, o movimento das Sufragistas, criando ainda em $1897^{16}$, pela educadora Millicent no Reino Unido alcançou grande adesão em praticamente todos os países. O movimento das Sufragistas no Brasil popularizou-se principalmente entre a elite política, característica que influenciou diretamente no sucesso do movimento em comparação com os demais países da América. A primeira mulher a votar no Brasil - Celina Guimarães Viana $^{17}$, moradora de Mossoró no Rio Grande do Norte, conseguiu uma autorização judicial para votar em 1928. No ano seguinte (1929) Alzira Soriano de Souza candidatou-se a prefeita de Lajes também no Rio Grande do Norte, tornando-se a primeira mulher eleita prefeita no

\footnotetext{
${ }_{17}^{16}$ Ano de fundação da União Nacional pelo Sufrágio Feminino.

17 OBLADEN, SD, p. 1.
} 
Brasil. Em 1931 Getúlio Vargas sob forte pressão do Movimento Sufragista autoriza o voto para as mulheres solteiras e viúvas que possuíam renda própria e para as casadas com autorização do marido. A medida não agradou, e no ano seguinte em 24 de fevereiro de 1932, o então presidente assinou o Decreto Lei n ${ }^{\circ} 21.076$ tornando o sufrágio universal no país.

\section{A educação feminina e a proteção à família.}

Apesar de permitir um grande avanço quanto à questão do Sufrágio, o período de gestão de Getúlio Vargas foi bastante desestimulador da educação feminina, e muitas alterações curriculares que restringiam o avanço das mulheres foram propostas. $\mathrm{O}$ ensino proposto na gestão de Gustavo Capanema (Ministro da Educação entre 1934 e 1945) e Vargas enfatizava os elementos de distinção entre o que se esperava para homens e mulheres. Nesse período, a infiltração das ideias fascistas em relação às mulheres e à família contribuíram para que diferenças no tratamento entre os gêneros fossem avivadas.

Gustavo Capanema, em seu projeto de Plano Nacional de Educação de 1937, por exemplo, previa a existência de um ensino doméstico, destinado às meninas de 12 a 18 anos, o qual equivaleria ao ensino médio masculino. Este tipo de ensino era considerado prático e profissionalizante e destinado às mulheres das classes populares.

O plano subdividia o ensino feminino em doméstico geral, doméstico agrícola e doméstico industrial. Cada uma das opções era organizada em dois ciclos. O primeiro ciclo prepararia as alunas para a vida doméstica, enquanto o segundo formaria professoras para dar continuidade às atividades do ensino doméstico. Este sistema não chegou a ser implantado na rede pública, mas foi adotado por muitas instituições católicas. Tais ideias, no entanto, são mantidas na escrita da Lei Orgânica do Ensino Secundário,

1- É recomendável que a educação secundária das mulheres se faça em estabelecimento de ensino secundário de exclusiva frequência feminina. 2- Nos estabelecimentos de ensino secundário frequentados por homens e mulheres, será a educação destas ministrada em classes exclusivamente femininas. Este preceito só deixará de vigorar por motivo relevante, e dada especial autorização do Ministério da Educação. 3- - Incluir-se-á na $3^{\circ}$ e na $4^{\circ}$ séries do curso ginasial e em todas as séries dos cursos clássico e científico a disciplina de economia doméstica. 4- A Orientação metodológica dos programas terá em mira a natureza da personalidade feminina e bem assim a missão da mulher dentro do lar. (Decreto-lei $n^{\circ} 4.244,9$ de abril de 1942).

Uma divisão tão acentuada dos papéis de cada gênero não encontrou amparo nas condições de financiamento do Estado e na sociedade que, segundo Capanema, não estava 
ainda preparada para conceber a importância da família. Nesse sentido, ele chega a aceitar a coeducação de gêneros em 1942, mas com diversas ressalvas e de forma excepcional.

O estado educará ou fará educar a infância e a juventude para a família. Devem ser os homens educados de modo a que se tornem plenamente aptos para a responsabilidade de chefes de família. Às mulheres será dada uma educação que as torne afeiçoadas ao casamento, desejosas da maternidade, competentes para a criação dos filhos e capazes da administração da casa. (CAPANEMA, in, SCHWARTZMAN, 2000, p. 14)

A questão da educação feminina era muito mais complexa que aparentava ser. Durante sua gestão, Vargas tomou a frente de uma imensa campanha pela institucionalização da família, aos moldes do que foi realizado por Mussolini na Itália. Em 1941, institui o Decretolei $\mathrm{n}^{\circ} 3200$, através do qual regulamenta o casamento de colaterais de $3^{\circ}$ grau, considerava sob os efeitos legais casamentos religiosos, previa o reconhecimento de filhos naturais e incentivava financeiramente o casamento e a procriação.

Segundo Schwartzman (2000), dentro deste plano de proteção à família, as mulheres tinham um papel muito importante, e sobre elas recaiam as maiores e mais penosas responsabilidades. Nessa perspectiva, campanhas foram criadas em favor do aumento da natalidade, leis censuravam a divulgação direta ou indireta de qualquer propaganda contra a noção de família, a propaganda de Estado se concentrava na redução do trabalho feminino fora do lar, incentivava a volta das famílias numerosas ao campo, proibia o uso de anticonceptivos e do aborto e sua divulgação na literatura, cinema, artes ou quaisquer outros meios.

Uma das forças que opera a favor da implantação desse sistema de conduta às mulheres e se insere ativamente na divulgação de uma estrutura familiar tendenciosa à submissão da mulher e sua contenção nos papéis de mãe e esposa é a Igreja Católica. Nesse sentido, a disciplina de ensino religioso se alinha ao Estado. A seguir traz-se a redação dos componentes curriculares da disciplina de ensino religioso, descritos por Capanema.

I) A moral cristã: a lei, a consciência. Pecado. Perfeição cristã. II) Em face da autoridade: pais e filhos. A hierarquia e os fiéis. Governantes e governados. Patrões e operários. III) Respeito à propriedade: o direito de propriedade. Pecados contra os bens do próximo. Restituição? Posição cristã em face do capitalismo e do comunismo. (CAPANEMA, In, SCHWARTZMAN, 2000, p. 13-14).

As relações entre Igreja e Estado que haviam sido reestabelecidas durante a gestão de Francisco Campos, na gestão de Capanema se materializam em um pacto pela institucionalização da interferência do Estado na vida familiar. Como vantagem direta a 
Igreja vê conservada a anuência do Estado ao ensino privado, uma de suas mais importantes atividades no país. Ainda durante o Estado Novo $(1937-1945)$ foi criado o Decreto Lei $n^{\circ}$ 3199, o qual proibia que as mulheres praticassem esportes considerados pelos homens no governo incompatíveis com as condições femininas, tais como "luta de qualquer natureza, futebol de salão, futebol de praia, pólo, pólo aquático, halterofilismo e beisebol”. (BRASIL, 1941, Decreto Lei n 3199).

\section{A Feminização do magistério}

O cerceamento a atuação social feminina, produzido pelas ações de proteção à família limitou em muito também as possibilidades de atuação profissional, sendo que o magistério se configura como uma das únicas opções, socialmente aceitas, de trabalho para mulheres, produzindo um processo conhecido como feminização do magistério. Processo no qual a profissão docente passou a ser associada a predicativos, ditos femininos, como o cuidado, a amorosidade, e com isso, também, ocorre uma defasagem salarial, visto que a docência passa as ser vista como uma função subalterna. Conforme Carvalho (1999) explica

\footnotetext{
Devemos entender que a feminização do magistério não se refere única e exclusivamente à presença massiva de mulheres na profissão docente, mas também à associação das práticas, atividades e significados desta profissão ao universo feminino, independente de quem os corporifica" (CARVALHO, 1999, p. 78)
}

Cabe destacar que esse processo apenas teve seu ápice durante o século $\mathrm{XX}$, pois seus alicerces surgiram, ainda, no século XIX. Segundo Faria Filho (2000, p. 164) "No Brasil, a maciça presença de mulheres no magistério do ensino primário refere-se a um longo processo que tem início durante o século XIX com as escolas de improviso, que não mantinham vínculos com o Estado, intensificando-se com a instituição das escolas seriadas após a República e com a progressiva extensão das escolas públicas.

De acordo com Louro (1989) e Demartini (1993), em 1830, o estado de São Paulo criou um projeto de lei que instituía as Escolas Normais. Tais escolas eram destinadas à formação de professores de ambos os sexos, no entanto, segundo os autores, dava-se preferência a presença feminina. As Escolas Normais chegaram a criar uma seção, exclusivamente, feminina no ano de 1880. Dessa forma, Demartini (1993, p. 6), afirma que, a Escola Normal era "uma das poucas oportunidades, senão a única, de as mulheres prosseguirem seus estudos além do primário". Dados trazidos pelo autor apontam ainda que "Em 1920, o Censo Demográfico indicava que 72,5\% do conjunto do professorado brasileiro 
do ensino público primário era composto por mulheres e, entre o total de docentes, sem distinção de graus de ensino, as mulheres somavam 65\%. (DEMARTINI 1993, p.7).

Com o avançar da década, esta tendência apenas se fortalece, e "no final da década de 1920 e início da de 1930, a maioria do magistério primário já era feminina”. Situação que perdura por todo o século XX.

\section{As Mulheres e a Guerra}

De acordo com informações levantadas por Heloneida Studart em sua obra Mulher: objeto de cama e mesa, publicada em 1974, no auge da Ditadura Militar, em 1872 a população feminina economicamente ativa no Brasil atingia cerca de 45\%; em 1920 essa proporção caia para 15,3\% e em 1970 andava pelos 20\% (STUDART, 1974 p. 48). A diferença acentuada entre um século e outro certamente está intimamente relacionada aos diversos conflitos armados ocorridos no período com destaque para a atuação dos regimes totalitários europeus: franquistas, Nazistas, fascistas e em específico à ditadura militar de inspiração em tais modelos no Brasil entre os anos de 1964 a 1985.

Para Gottfried Feder, líder nazista, "o judeu roubou as nossas mulheres pela democracia sexual. Nós a jovem geração, devemos levantar-nos para matar o dragão. A fim de fazer reviver o que há de mais sagrado no mundo: a mulher serva e escrava" (FEDER In STUDAR, 1974, p. 35). Segundo Studart, os líderes nazistas propunham às mulheres alemãs os três KKK: Kind (Criança), Kirche (Igreja) e Küche (Cozinha). Durante o regime todas as possibilidades de estudo e atuação na produção foram proibidas às mulheres. Sendo que "em junho de 1933, o Estado Nazi dispensou todas as mulheres funcionárias, mesmo as professoras, substituindo-as por homens" (STUDART, 1974, p. 36). O mais interessante nesse processo fora sem dúvida o vultuoso apoio das mulheres, na edificação do III Reich, em que abriam mão da liberdade e de todas as possibilidades de crescimento econômico e social, conquistados arduamente, para se manterem na segurança dos papeis de mães, sem responsabilidades sobre os rumos trilhados pelo nazismo.

Foi publicado um decreto proibindo que houvessem dois salários no mesmo lar, seguido de outro, dando prioridade absoluta ao homem sobre a mulher na ocupação de qualquer emprego remunerado. Foram suprimidas as bolsas de estudo no ensino secundário para as meninas e o ingresso na faculdade foi dificultado de todas as maneiras às estudantes. Ao mesmo tempo, uma campanha publicitária sem precedentes convocava as mulheres para serem apenas mães dos cidadãos do III reich. O papel de mãe foi sacralizado e mitificado ao máximo. Nunca, como nessa época de pesadelo, a mulher foi tão planificadamente reduzida à sua condição de fêmea da espécie. Sem trabalho e, portanto, sem possibilidade de amadurecimento, ela se reduziu á função reprodutora e conformou-se à rotina do lar, onde fazia torta e 
passava o enxergão, enquanto as soviéticas iam para a universidade e as norteamericanas entravam em massa nas fábricas e escritórios. (SUDART, 1974 p. 36-37, grifos da autora).

Tais medidas também exerceram forte influência na formação do pensamento acerca das mulheres no Brasil, visto que em todas as pesquisas realizadas durante o século XX no país as mulheres despontavam como maioria entre os analfabetos e desempregados. Sendo que apenas $25 \%$ das mulheres estavam empregadas e destas metade exercia a função de empregada doméstica, função cuja regulamentação deixava em aberto especificidades tais como remuneração básica, jornada mínima de trabalho, direito à Fundo de Garantia, sindicato, ou seja, a possibilidade de atuação mais recorrente se aproximava à escravidão e não oferecia as menores condições para a independência feminina. As opções se dividiam entre servir ao lar, filhos e um marido ou ao lar, filhos e maridos de outra.

Para além da influência das ideologias totalitárias, a entrada do Brasil na Segunda Guerra (1939 - 1945) interferiu diretamente nas condições de atuação feminina. Em 28 de agosto de 1942 a primeira dama do Brasil - Darcy Vargas - criou a Legião Brasileira de Assistência (LBA), instituição assistencial que recrutava mulheres para oferecer amparo aos soldados. Segundo dados trazidos por Simili (2008, p. 444)

\footnotetext{
Para desenvolver o projeto assistencial, ela contou com o apoio do empresariado, do Governo e principalmente das mulheres provenientes da elite e da classe média do Rio de Janeiro, população composta por jovens e senhoras. Somente na capital carioca, onde funcionava a sede da instituição, milhares de personagens femininas transformaram-se em voluntárias da Legião Brasileira de Assistência. Para elas, a instituição criou uma variedade de cursos preparatórios, por exemplo, os de formação de voluntárias da defesa passiva, de alimentação, para samaritanas socorristas, para visitadoras e educadoras sociais, entre outros. Além dos cursos, em nome da assistência social de guerra, centenas de mulheres foram mobilizadas para os mais diversos serviços, como os de costura e produção de bandagens, que serviram de roupas e materiais hospitalares e eram doados aos soldados mobilizados e seus familiares para serem empregados no atendimento médico hospitalar no front de guerra.
}

Ainda nesse período lançaram-se no país as campanhas 'Horta da Vitória' que pretendia transformar todas as mulheres em cultivadoras de alimentos como hortaliças e leguminosas em seus quintais para auxiliar na alimentação dos combatentes; e 'Madrinhas dos Combatentes', esta campanha, por sua vez, buscava mobilizar mulheres para escrever cartas aos soldados e/ ou participar de programas radiofônicos transmitindo mensagens de estímulo e conforto para os combatentes. 
A presença feminina fora do lar é justificada pelas necessidades da guerra, somente assim a participação feminina é permitida, porque no âmbito da instituição, tal como na família, as mulheres deviam dedicar-se aos cuidados com os outros. Para viabilizar os cuidados femininos na guerra, estabelecesse uma divisão de tarefas consoantes os gêneros: enquanto os homens lutam, e participam da Guerra, no front, as mulheres cuidam daqueles e daquilo que foram por eles deixados no país. (SIMILI, 2008, p. 456).

Com a instituição da Ditadura Militar em 1964 dá se início a um período de intenso retrocesso para as condições de vida das mulheres no país. No mesmo ano o Conselho Nacional de Desportos (CND) proíbe a prática do futebol feminino. Um capítulo à parte são os métodos de torturas utilizados contra as mulheres prisioneiras políticas, que incluem de choque elétricos em gestantes a introdução de objetos e animais na vagina das vítimas. Segundo informações divulgadas no site Torre das Donzelas, extraídas da obra Mulheres, ditaduras e Memórias de Susel Oliveira da Rosa:

\begin{abstract}
Torturar através de violação, mutilação, humilhação, insultos e ameaças sexuais caracteriza a tortura baseada no gênero, sistematicamente utilizada contra as mulheres, apesar de, muitas vezes, homens e meninos também serem vítimas desse tipo de tortura; acrescentando-se especificamente às mulheres os choques elétricos em grávidas e introdução de objetos na vagina. Torturas cometidas pelos agentes do Estado, aqueles que Martha Huggins em Operários da Violência denomina de perpetradores de atrocidades que tinham o aval de uma imensa gama de facilitadores de atrocidades. Funcionários de um Estado de exceção que, durante a ditadura militar, tinham licença especial para matar, torturar ou estuprar. Agentes que viam as mulheres militantes como desviantes, aquelas que renegavam sua natureza ousando ocupar o espaço da luta política. (ROSA, 2013, apud TORRE DAS DONZELAS)
\end{abstract}

No entanto, o período foi bastante rico em registros de participações femininas em movimentações e levantes contra a censura, a violão de direitos e na busca a desaparecidos. Para a Ditadura Militar no Brasil, “as mulheres militantes encarnavam um papel duplamente transgressor: transgrediam enquanto agentes políticos ao se insurgirem contra a ditadura" e ao mesmo tempo também "transgrediam ao romper com os padrões tradicionais de gênero ao ocupar o espaço público e a arena política" (ROSA, 2013, p. 209).

Nesse sentido, "o movimento feminista brasileiro, ao reflexo do feminismo latinoamericano, apenas se consolidou enquanto um movimento de massa em meados da década de 1970, no contexto da luta contra o regime militar" (SENKEVICS, 2013, p.1). Nos anos finais da Ditadura Militar, grupos de mulheres se organizam em torno de questões como a proibição da violência contra a mulher, através do lema: Quem ama não mata, popular no ano de 1980, sendo que em 1985 é criada a primeira Delegacia de Atendimento Especializado à mulher, a DEAM. 


\section{Conclusões}

No início do século passado figuras femininas se mobilizaram em torno de pautas como o direito ao divórcio, o fim do casamento burguês sob a égide do Estado, a conquista de direitos trabalhistas, a defesa do amor livre e da coeducação de gêneros. Muitas destas pautas foram alcançadas no decorrer do século XX e outras ganharam força após a Revolução Sexual da década de 1960, principalmente a luta pela liberdade sexual e reprodutiva das mulheres. No entanto, nas primeiras décadas do século XXI percebe-se um renascimento das organizações feministas ou neofeministas, comprometidas com o fim da violência sexual e da violência doméstica. Estas se destacam pelo uso do corpo como forma de expressão, pela utilização das mídias digitais e redes sociais e pelo entrelaçamento a outros movimentos, como o LGBT, ambientais, antirracistas, políticos e de fortalecimento de comunidades periféricas, indígenas e quilombolas. Nesse sentido, este estudo busca desenhar o papel do feminismo e da mulher na contemporaneidade a partir das origens do movimento.

Compõem como fatores relevantes para a compreensão das peculiaridades do feminismo atual a velocidade da circulação de informações e o alcance permitido pelas mídias sociais, a emergência de grupos periféricos com questões diversas e o desenvolvimento de atividades que giram em torno de causas específicas de cada segmento envolvido com a problematização das questões de gênero. Dessa forma apresenta-se como uma necessidade atual se reconhecer a existência de feminismos para que se possa contemplar a pluralidade de questões que perpassam as relações de gênero na contemporaneidade.

A facilidade com que as informações circulam e alcançam destinatários diversos confere aos movimentos feministas uma visibilidade sem precedentes ao mesmo tempo em que ajuda a disseminar um senso comum hipócrita sobre as reivindicações dos grupos, recaindo na pulverização de ataques embasados em argumentos religiosos, paternalistas e que acabam por manter circulando uma imagem da mulher feminista como agressiva, violenta e escandalosa, cujas intenções reais recaem na extinção da família, na promiscuidade e na dominação masculina, entre outros. A utilização de redes sociais ainda possibilita que a situação da mulher apareça com nuances mais vivos, dando voz a mulheres que relatam em tempo real as inúmeras violências a que estão expostas em casa, nas ruas, no trabalho, pela propaganda, pelo estilo de vida, crenças, vestimentas, atitudes e na própria realidade virtual. Nesse sentido é importante pensar se tamanha exposição trabalha para modificar a situação ou acaba por naturalizá-la. 


\section{Referências}

A VIDA n ${ }^{\circ}$ 2. O desperdício da enerjia feminina. [sic]. 1914. Rio de Janeiro, 28 de Fev., p.7.

A VIDA n ${ }^{\circ}$ 3. O desperdício da enerjia feminina. [sic] 1915. Rio de Janeiro, 31 de Mar., p. 5 .

A VIDA nº 4. Periódico Anarquista. 1915. Rio de Janeiro, 31 de Mar., p54.

BRASIL. Decreto Imperial, de 15 de outubro de 1827. Manda criar escolas de primeiras letras em todas as cidades, vilas e lugares mais populosos do Império.

Decreto no 7.247, de 19 de abril de 1879. Reforma o ensino primário e secundário no município da Corte e o superior em todo o Império.

Decreto-lei $\mathbf{n}^{\circ}$ 3200, de 19 de abril 1941. Dispõe sobre a organização e proteção da família.

Decreto Lei $\mathbf{n}^{\circ}$ 3199, de 14 de abril de 1941. Estabelece as bases de organização dos desportos em todo o pais.

CARVALHO, Marília Pinto de. No coração da sala de aula: gênero e trabalho docente nas séries iniciais. São Paulo: Xamã, 1999.

CORTÊS, Giovana Xavier da Conceição. As Inimigas da pátria: Medicina Social e corporeidade negra nas últimas décadas do século XIX. 'Usos do Passado' - XII Encontro Regional de História ANPUH-RJ. 2006.

DAVIES, Norman. A Europa em Guerra. Edições 70: Lisboa, 2006.

DIAS, Mabel. Mulheres Anarquistas: o resgate de uma história pouco contada. João Pessoa: Imprensa Marginal, 2003.

FARIA FILHO, Luciano; VIDAL, Diana Gonçalves. Os tempos e os espaços escolares no processo de institucionalização da escola primária no Brasil. Revista Brasileira de Educação, Número Especial, p. 19-34, 2000.

OBLADEN, Roberta. Mulheres e política. Disponível em:

http://www.educacional.com.br/reportagens/eleicoes_mulheres-politica/parte-03.asp. Acesso Em: 23 de jan. 2017.

KARAWEJCZYK, Mônica. Bertha Lutz e Maria Lacerda de Moura - Uma Parceria Inusitada. In revista Gênero: Niterói, 2014. v.14, n.2, p. 105-124 1.sem.

ROSA, Susel Oliveira da. Mulheres, ditaduras e memórias: "não Imagine que precise ser triste para ser militante". São Paulo: Intermeios, 2013.

SENKEVICS, Adriano. Mulheres e feminismo no Brasil: um panorama da ditadura à atualidade. Disponível em: https://ensaiosdegenero.wordpress.com/2013/07/11/mulheres-efeminismo-no-brasil-um-resumo-da-ditadura-a-atualidade/. Acesso em: 8 de out. de 2017 
SCHWARTZMAN, Simon. BOMENY, Helena Maria Bousquet; COSTA, Vanda Maria Ribeiro. Tempos de Capanema. São Paulo: Paz e Terra: Fundação Getúlio Vargas, 2000. CAPANEMA, In, SCHWARTZMAN, 2000, p. 13-14

SIMILI, Ivana Guilherme. Educação e produção de moda na Segunda Guerra Mundial: as voluntárias da Legião Brasileira de Assistência. Cadernos pagu (31), julho-dezembro de 2008:439-469.

STUDART, Heloneida. Mulher: objeto de cama e mesa. Petrópolis: Vozes, 1974. TORRE DAS DONZELAS. O Papel da Mulher na Ditadura Militar. Disponível em: http://www.torredasdonzelas.com.br/o-papel-da-mulher-na-ditadura-militar/. Acesso em: 15 de Nov. de 2016.

VARELA, Júlia. Nacimiento de la Mujer Burguesa: el cambiante desequilíbrio de poder entre los sexos. Madri: La piqueta, 1997.

VIANNA, Claudia Pereira. A feminização do magistério na educação básica e os desafios para a prática e a identidade coletiva docente. In: YANNOULAS, Silvia Cristina (Org.). Trabalhadoras: análise da feminização das profissões e ocupações. Brasília, DF: Abaré, 2013. Downloaded from: Biblioteca Digital da Produção Intelectual - BDPI, Universidade de São Paulo. 